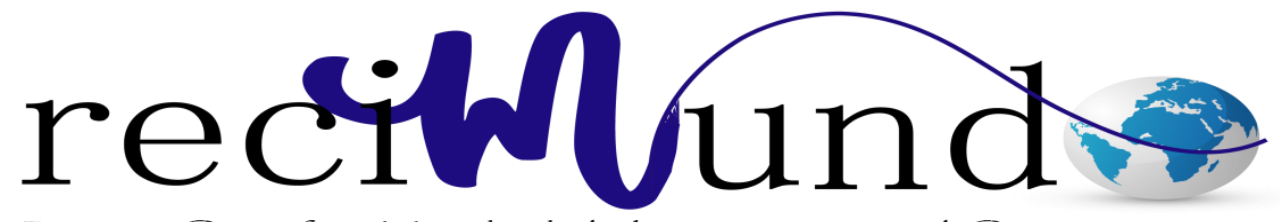

Revista Cientifica Mundo de la Investigación y el Conocimiento

Harry Francisco Álvarez Castro a; Franklin Valdez Aguagallo ${ }^{\text {b; }}$ Lady Diana Ramírez Moran $^{\mathrm{c}}$

Escala de Alvarado como método de diagnóstico en apendicitis aguda

Revista Científica Mundo de la Investigación y el Conocimiento. Vol. 2 núm.2, mayo, ISSN: 2588-073X, 2018, pp. 496-524

DOI: 10.26820/recimundo/2.(2).2018.496-524

Editorial Saberes del Conocimiento

Recibido: 05/12/2017

Aceptado: 15/04/2018

a. Universidad de Guayaquil; harry.alvarezc@ug.edu.ec

b. Universidad de Guayaquil ; franklin.valdeza@ug.edu.ec

c. Universidad de Guayaquil; $\underline{\text { lady.ramirezm@ug.edu.ec }}$ 


\section{Escala de Alvarado como método de diagnóstico en apendicitis aguda}

Vol. 2, núm. 2., (2018)

Harry Francisco Álvarez Castro; Franklin Valdez Aguagallo; Lady Diana Ramírez Moran

\section{RESUMEN}

La apendicitis aguda es la patología quirúrgica más frecuentemente evaluada en los servicios de urgencia y ocupa el primer lugar de las intervenciones quirúrgicas que se realizan en estos servicios en todo el mundo. También, ocupa el primer lugar en la mente del cirujano de urgencia cuando evalúa un paciente con dolor abdominal. El diagnóstico de apendicitis es principalmente clínico. Con la intención de disminuir las implicaciones en términos de costo económico y las complicaciones de la cirugía en pacientes sin apendicitis o pacientes con apendicitis complicada, se han incorporado diversos estudios de imagen, laboratorio y técnicas laparoscópicas que contribuyen al diagnóstico y eventual tratamiento de la apendicitis. Metodología: El presente artículo científico tiene un enfoque netamente cualitativo, donde se hizo la revisión de literatura acerca de la práctica docente frente a la formación por competencias en la educación superior. Para la realización de la presente investigación, se consideró, información confiable sobre trabajos plasmados, versados en este tema, se utilizaron informaciones bibliográficas, consultas electrónicas, se la obtuvo de libros electrónicos, artículos científicos y revistas. Conclusiones: En el presente artículo se logró establecer, que mediante la escala de Alvarado los pacientes presentan un puntaje alto con el que es suficiente para realizar un procedimiento quirúrgico.

Palabras clave: Escala de Alvarado; urgencias médicas; apendicitis. 


\title{
Escala de Alvarado como método de diagnóstico en apendicitis aguda
}

Vol. 2, núm. 2., (2018)

Harry Francisco Álvarez Castro; Franklin Valdez Aguagallo; Lady Diana Ramírez Moran

\begin{abstract}
Acute appendicitis is the surgical pathology most frequently evaluated in the emergency services and occupies the first place in the surgical interventions performed in these services throughout the world. Also, it occupies the first place in the mind of the emergency surgeon when evaluating a patient with abdominal pain. The diagnosis of appendicitis is mainly clinical. With the intention of reducing the implications in terms of economic cost and the complications of surgery in patients without appendicitis or patients with complicated appendicitis, several imaging, laboratory and laparoscopic techniques have been incorporated that contribute to the diagnosis and eventual treatment of appendicitis. . Methodology: The present scientific article has a purely qualitative approach, where the literature review was made about the teaching practice in front of the training by competences in higher education. For the realization of the present investigation, it was considered, reliable information about works captured, versed in this topic, bibliographic information, electronic consultations were used, it was obtained from electronic books, scientific articles and magazines. Conclusions: In the present article it was possible to establish that by means of the Alvarado scale, patients present a high score with which it is sufficient to perform a surgical procedure.
\end{abstract}

Keywords: Alvarado scale; medical emergency; appendicitis. 


\section{Escala de Alvarado como método de diagnóstico en apendicitis aguda}

Vol. 2, núm. 2., (2018)

Harry Francisco Álvarez Castro; Franklin Valdez Aguagallo; Lady Diana Ramírez Moran

\section{Introducción.}

La apendicitis aguda es la patología quirúrgica más frecuentemente evaluada en los servicios de urgencia y ocupa el primer lugar de las intervenciones quirúrgicas que se realizan en estos servicios en todo el mundo. También, ocupa el primer lugar en la mente del cirujano de urgencia cuando evalúa un paciente con dolor abdominal. El diagnóstico de apendicitis es principalmente clínico. Con la intención de disminuir las implicaciones en términos de costo económico y las complicaciones de la cirugía en pacientes sin apendicitis o pacientes con apendicitis complicada, se han incorporado diversos estudios de imagen, laboratorio y técnicas laparoscópicas que contribuyen al diagnóstico y eventual tratamiento de la apendicitis. (BELTRÁN S, VILLAR M, \& TAPIA, 2004)

La experiencia del cirujano en el diagnóstico clínico del dolor abdominal es el mejor examen al que puede ser sometido el paciente. La idea de aplicar un score diagnóstico a una determinada patología no es nueva, múltiples autores han investigado, elaborado y validado diversos scores en patología quirúrgica, incluyendo la apendicitis aguda. En 1986, Alvarado publicó el clásico score que lleva su epónimo para el diagnóstico de apendicitis aguda. Desde entonces se ha publicado una gran cantidad de estudios. Los scores diagnósticos de apendicitis aguda, tienen en común la asignación de un valor determinado a parámetros clínicos y de laboratorio, con la intención de aplicar el puntaje obtenido de la suma de estos parámetros, a una escala de probabilidad, en cada paciente en el cual se sospecha una apendicitis aguda y de esta manera orientar al médico o al cirujano, en el diagnóstico de cada caso particular. (Sanabria, Domínguez, Bermúdez, \& Serna, 2007) 


\section{Escala de Alvarado como método de diagnóstico en apendicitis aguda}

Vol. 2, núm. 2., (2018)

Harry Francisco Álvarez Castro; Franklin Valdez Aguagallo; Lady Diana Ramírez Moran

La aplicación sistemática de un score diagnóstico de apendicitis aguda en los servicios de urgencia es factible, así se ha demostrado, y permite la identificación adecuada de pacientes con una posible apendicitis aguda que requieren de cirugía urgente, disminuyendo consecuentemente el margen de error diagnóstico y por lo tanto las posibles implicaciones económicas y legales. Nos propusimos un estudio en un plazo de un año con el fin de identificar y diagnosticar con mayor precisión la apendicitis aguda poniendo en consideración la utilización de la escala de Alvarado vs ecografía abdominal. (López Abreu, Gómez, Hernández Paneque, \& Pérez Suárez, 2016)

\section{Metodología.}

El presente artículo científico tiene un enfoque netamente cualitativo, donde se hizo la revisión de literatura acerca de la práctica docente frente a la formación por competencias en la educación superior. Para la realización de la presente investigación, se consideró, información confiable sobre trabajos plasmados, versados en este tema, se utilizaron informaciones bibliográficas, consultas electrónicas, se la obtuvo de libros electrónicos, artículos científicos y revistas.

\begin{tabular}{|c|c|c|}
\hline Libros & Artículos científicos & Revistas \\
\hline 11 & 12 & 10 \\
\hline \multicolumn{3}{|c|}{ 33 bibliografías } \\
\hline
\end{tabular}

En la investigación se utilizaron alrededor de 11 libros donde se encontró información acerca de la educación superior. 12 artículos científicos fueron tomados de referencia. De igual manera los contenidos difundidos en revistas fueron muy importantes, en promedio 33 


\section{Escala de Alvarado como método de diagnóstico en apendicitis aguda}

Vol. 2, núm. 2., (2018)

Harry Francisco Álvarez Castro; Franklin Valdez Aguagallo; Lady Diana Ramírez Moran

documentos fueron tomados en consideración acerca de los principales logros en la educación superior representando información importantísima para analizar este tema de manera general.

\section{Desarrollo.}

Estudios han demostrado resultados significativos en cuanto a la eficiencia de la educación superior en un país, en el que constantemente se realizan cambios estructurales a la hora de impartirse conocimientos es por ello que.

\section{Apendicitis aguda}

\section{Definición e historia}

La apendicitis aguda es el proceso inflamatorio del apéndice vermicular secundario a la obstrucción mecánica de su luz. Resulta interesante revisar la historia de este órgano y su patología, pues muchos de sus mitos y retos se relacionan con aspectos controvertidos reflejados en dos apreciaciones contrapuestas: la de Fitz que se refiere, en 1886, a lo fácil de diagnosticar la apendicitis y la de Neblett que, un siglo más tarde, nos pone de manifiesto que al momento de hacer el diagnóstico de la enfermedad en niños menores de 3 años, el órgano está usualmente perforado. (Young, 2014) (Cope, 1947)

La apendicitis (AP) constituye un proceso inflamatorio agudo iniciado por la obstrucción de la luz apendicular cecal y que, librado a su evolución espontánea, puede originar la perforación con la consiguiente peritonitis. Se estima que 5\% de la población la padecerá en algún momento de su vida. En 1886 fue reconocida como entidad clínica y anatomopatológica por Reginald Heber Fitz (1843-1913). (Cope, 1947) 


\section{Escala de Alvarado como método de diagnóstico en apendicitis aguda}

Vol. 2, núm. 2., (2018)

Harry Francisco Álvarez Castro; Franklin Valdez Aguagallo; Lady Diana Ramírez Moran

Durante el siglo XIX Goldbeck reportó una serie de 30 casos y con mucha acuciosidad describió los aspectos clínicos de la apendicitis, a pesar de lo cual continuó asumiendo que el problema se originaba en el ciego. Este concepto se mantuvo durante los siguientes 60 años 4 en los que la enfermedad apendicular quedó cubierta bajo el amplio manto del término tiflitis, mientras que al proceso inflamatorio circundante, propio de sus complicaciones, se lo denominó peritiflitis. Este hecho demuestra que los cirujanos no reconocían sino la severa inflamación del ciego y área circunvecina. (Rengel, 2016)

Para 1886, Reginald H. Fitz describe el origen apendicular de la tiflitis y peritiflitis, así como los signos y síntomas tempranos de la enfermedad a la que denominó apendicitis, que a su juicio explicaba los otros términos que no eran otra cosa que diferentes etapas de un mismo proceso y advertía sobre "la facilidad de su diagnóstico, los síntomas urgentes y la necesidad de una laparotomía para su tratamiento", incluyendo en la literatura quirúrgica un nuevo término: la apendicectomía. (Fallas González, 2012)

\section{Epidemiología}

La literatura reporta que en los Estados Unidos aparecen aproximadamente 297000 casos anuales de apendicitis aguda (47\% de las 550000 apendicetomías anuales) y se considera que 1 de cada 15 personas desarrollará apendicitis en algún momento de su vida. Se describió una clara tendencia decreciente entre los años 1940 y 1960 y es aceptado que la enfermedad es más frecuente en hombres (3:2), rara en infantes, muy importante como causa de enfermedad en adolescentes y adultos jóvenes hasta los 30 años, luego de lo cual nuevamente disminuye en frecuencia a la vez que la relación entre hombres y mujeres se iguala 1:1. Sin embargo, la gran mayoría de referencias hablan más de la apendicectomía que de la apendicitis aguda. (Luz, 2017) 


\section{Escala de Alvarado como método de diagnóstico en apendicitis aguda}

Vol. 2, núm. 2., (2018)

Harry Francisco Álvarez Castro; Franklin Valdez Aguagallo; Lady Diana Ramírez Moran

\section{Etiología}

La etiología de la apendicitis aguda es siempre obstructiva. Partiendo del antecedente de que la enfermedad tiene su mayor frecuencia entre los 11 y los 30 años y que dentro de estas edades el pico de incidencia se ubica en los primeros años de la adolescencia, podemos decir que la causa más común de obstrucción apendicular es la hiperplasia del tejido linfoide. Aun cuando se ha demostrado la presencia de bacterias (enterococcus, estreptococcus beta hemolíticus, Escherichia coli), no ha sido posible confirmar si éstas invaden directamente la pared apendicular para causar apendicitis o si llegan por vía hemática o linfática tras el inicio de la enfermedad. Sin embargo, hay un dato importante que se fundamenta en algunos estudios que han demostrado hasta un 5\% de participación directa de Yersinia enterocolitica en la etiopatogenia de la apendicitis aguda. (RODRÍGUEZ VEGA, 2014)

La apendicitis resulta de la obstrucción de la luz del apéndice. Esta obstrucción puede ser por hiperplasia linfoide (60\%), fecalito o estasis fecal (35\%), cuerpo extraño (4\%), y tumores (1\%). La obstrucción luminal incluyen la hiperplasia linfoide, secundaria a enfermedad inflamatoria intestinal o infecciones (común en la infancia y adultos jóvenes), estasis fecal y fecalitos (común en ancianos), parásitos (especialmente en países orientales), o, menos frecuente, cuerpos extraños y neoplasias. Los fecalitos se forman cuando las sales de calcio y los restos fecales hacen capas sobre la materia fecal espesa en la luz apendicular. La hiperplasia linfoide es asociada a varias alteraciones inflamatorias o infecciones como enfermedad de Crohn, gastroenteritis, amebiasis, infecciones respiratorias, etc.

La obstrucción de la luz apendicular es menos frecuente y se asocia a bacterias (Yersinia, adenovirus, citomegalovirus, actinomicosis, Mycobacteria, Histoplasma), parásitos (ej., 


\section{Escala de Alvarado como método de diagnóstico en apendicitis aguda}

Vol. 2, núm. 2., (2018)

Harry Francisco Álvarez Castro; Franklin Valdez Aguagallo; Lady Diana Ramírez Moran

esquistosomas, áscaris, Strongyloides stercoralis), cuerpos extraños (ej., perdigones, dispositivos intrauterinos, carbón activado), tuberculosis, y tumores.

\section{Fisiopatología}

Para una cabal comprensión de los hechos patológicos asociados con la apendicitis aguda es menester comprender adecuadamente algunas de las características morfológicas y funcionales del apéndice normal. Empecemos por recordar que se trata de un órgano rudimentario que posee una estructura microscópica especial en donde destacan fibras de colágeno horizontales, que sólo dejan que el órgano se distienda pasivamente en forma muy limitada y como su mucosa carece de pliegues, no puede ceder con facilidad al aumento de presión en su luz. Por otra parte, la capacidad promedio de la luz apendicular es de apenas $1 \mathrm{~mL}$ y cada día este órgano elabora 2 a $3 \mathrm{~mL}$ de moco. Por su escasa capacidad elástica, un almacenamiento de $0,5 \mathrm{~mL}$ adicionales puede causar un incremento de la presión de hasta unos $45 \mathrm{mmHg}$, fenómeno explicado por la ley de Laplace. Los eventos fisiopatológicos de la apendicitis aguda, resumidos en el cuadro \#1, demuestran que esta es una enfermedad caracterizada por una evolución secuencial y por etapas, cuya expresión clínica traduce de manera más o menos constante la gravedad del daño tisular. Clásicamente se consideran dos etapas y cuatro estadios de la enfermedad. La etapa no complicada incluye las formas focal (inicial o catarral) y supurativa (flemonosa) en tanto que la etapa complicada engloba a la apendicitis necrótica (gangrenosa) y perforada. Como mencionamos anteriormente, la apendicitis aguda se inicia con la obstrucción de la luz apendicular, lo cual genera un proceso inflamatorio limitado que se caracteriza por la presencia notable de polimorfonucleares en la mucosa y menos intensa en la submucosa y la muscular, asociado a un aspecto granuloso, opaco y rojizo de la 


\section{Escala de Alvarado como método de diagnóstico en apendicitis aguda}

Vol. 2, núm. 2., (2018)

Harry Francisco Álvarez Castro; Franklin Valdez Aguagallo; Lady Diana Ramírez Moran

serosa. Esta descripción corresponde a la apendicitis focal aguda y categóricamente establece que el diagnóstico histopatológico de esta enfermedad se basa en la presencia de polimorfonucleares por lo menos hasta la submucosa. (Sakellaris, Tilemis, \& Charissis , 2005)

La obstrucción de la luz apendicular no impide que esta siga produciendo moco y puesto que se trata de un órgano terminal, la obturación en cualquier punto una forma de "obstrucción en asa cerrada", lo que implica un incremento progresivo de la presión intraluminal que en un momento determinado puede superar el valor de la presión arterial diastólica. Como puede colegirse, una presión incrementada a ese nivel colapsa los vasos venosos y empobrece el retorno sanguíneo, provocando congestión y edema tisular, acumulación de toxinas y con ello un buen substrato para la proliferación bacteriana. La mezcla de células muertas y productos tóxicos con las bacterias locales da como resultado la formación de pus. Debido a que la circulación arterial todavía está conservada, se incrementará importantemente la congestión y dará lugar a la aparición de exudado en el área periapendicular. Los cortes histológicos pondrán de manifiesto una infiltración de todas las capas del apéndice por parte de los polimorfonucleares y la serosa impregnada de gleras fibrinopurulentas, lo que establece el diagnóstico de apendicitis supurativa aguda. Un hecho adicional deriva de la continua secreción de moco, incremento de la presión intraluminal y colapso del retorno venoso: la insuficiencia del riego arterial bien sea por compresión, o por ineficacia para progresar hacia los capilares. La isquemia consecuente termina por destruir la lábil mucosa apendicular con lo que se destruye la barrera mecánica al paso de bacterias y por ende éstas se diseminan por todas las capas del órgano, generando una exacerbación de la respuesta inflamatoria, mayor edema y mayor incremento de la presión. En un determinado momento el riego arterial fracasará y por las características anatómicas de la arteria 


\section{Escala de Alvarado como método de diagnóstico en apendicitis aguda}

Vol. 2, núm. 2., (2018)

Harry Francisco Álvarez Castro; Franklin Valdez Aguagallo; Lady Diana Ramírez Moran

apendicular la mayor afectación recaerá en el borde antemesentérico, en el cual aparecerán parcelas elipsoidales de necrosis parietal sólo cubierta por la serosa. Como la serosa es una membrana semipermeable, no impide el paso de bacterias y toxinas que transforman el exudado del estadio anterior en pus. El estudio patológico demuestra un apéndice muy grueso, con parcelas de color verde - negruzco, serosa gris y deslustrada, gran infiltrado inflamatorio en todas las capas y necrosis ulcerada de la mucosa encontrándonos ante el estadio de apendicitis aguda necrótica.

Como paso final la serosa perderá su capacidad de contención y se romperá, dejando paso libre al contenido contaminado que se encontraba en el apéndice. Cuando la apendicitis se complica puede ocurrir que las vísceras cercanas rodeen el proceso para formar un plastrón con o sin absceso o que el trastorno permanezca libre, de tal manera que cuando se produce la ruptura hay lugar a una gruesa contaminación local o general de la cavidad peritoneal. La apendicitis aguda perforada aparecerá al estudio anatomopatológico con todas las características descritas para la forma necrótica, más una extensión del infiltrado inflamatorio al mesoapéndice, en el que pueden formarse microabscesos. Todas las capas del órgano se ven destruidas y adelgazadas, de manera particular a nivel de la perforación. 


\section{Escala de Alvarado como método de diagnóstico en apendicitis aguda}

Vol. 2, núm. 2., (2018)

Harry Francisco Álvarez Castro; Franklin Valdez Aguagallo; Lady Diana Ramírez Moran

\section{Cuadro 1: Eventos fisiopatológicos de la apendicitis aguda}

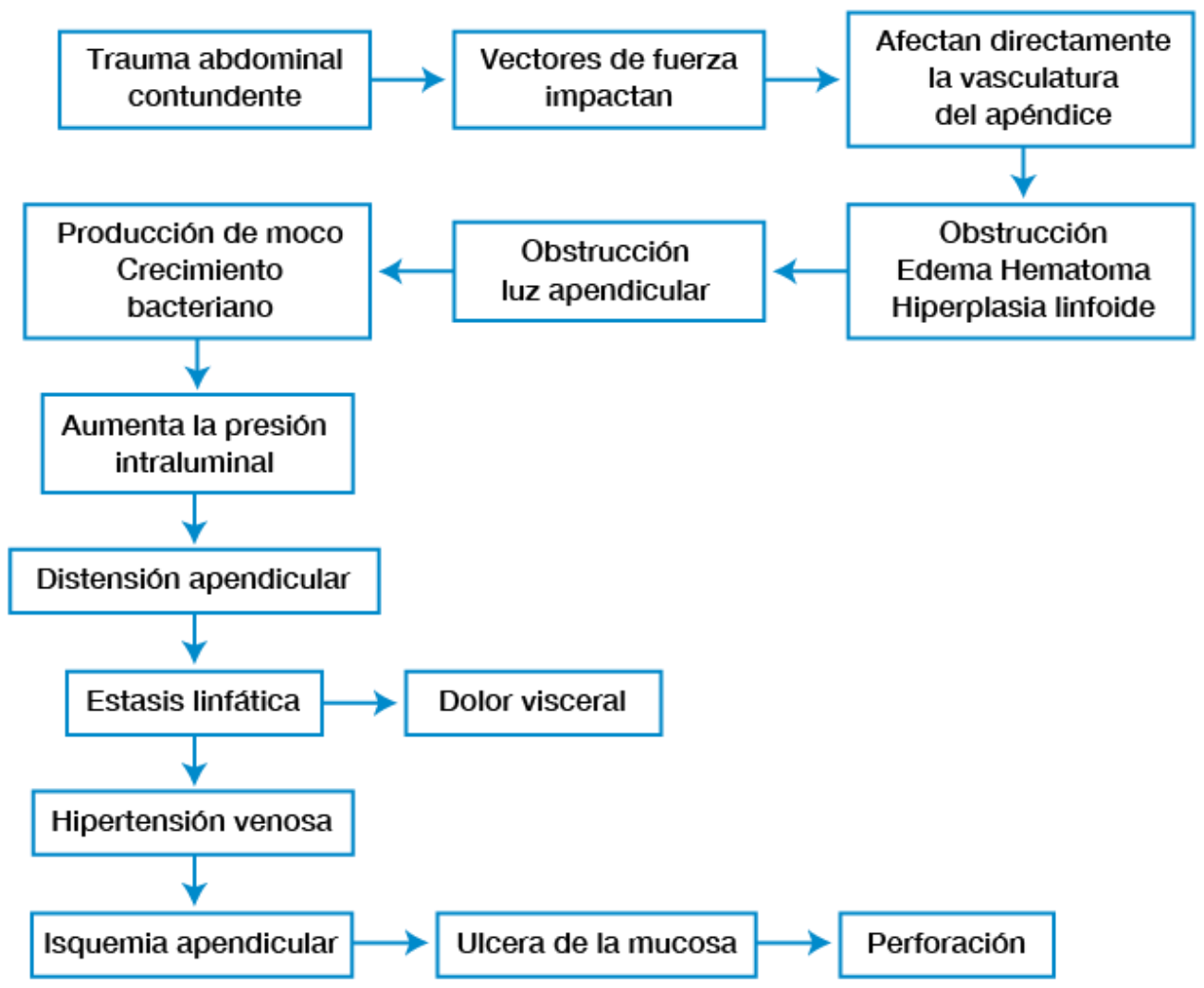

\section{Cuadro Clínico}

La clásica cronología de Murphy, dolor epigástrico o periumbilical, seguido de náusea, migración del dolor al cuadrante inferior derecho, vómito tardío y fiebre, sólo aparece en un 50\% de los pacientes.

El síntoma más temprano de apendicitis aguda es la anorexia, que traduce una respuesta peritoneal temprana cuyo objetivo es advertir al organismo que impida el uso del tracto digestivo. Clásicamente se insiste que la falta de este síntoma debe poner en duda el diagnóstico, pero hay quienes observan que el síntoma puede faltar en más del $40 \%$ de casos. Náusea y vómito constituyen la prosecución de un mismo síntoma, la anorexia y por lo tanto su 


\section{Escala de Alvarado como método de diagnóstico en apendicitis aguda}

Vol. 2, núm. 2., (2018)

Harry Francisco Álvarez Castro; Franklin Valdez Aguagallo; Lady Diana Ramírez Moran

explicación es similar. Debe recordarse que la intensidad del vómito guarda relación con la gravedad de la enfermedad y que, por otra parte, puede aparecer como una respuesta refleja al dolor y por ende nunca lo precede. El vómito ocurre en un $50 \%$ a un $70 \%$ de casos y característicamente no alivia el dolor. La constipación puede ser el síntoma inicial en algunos pacientes ancianos, pero debe compararse siempre con su hábito. También puede ser un síntoma presente en los niños. Es menos frecuente observar diarrea y su aparición se relaciona con un proceso irritante de vecindad sobre el íleon o el recto y se asocia con perforación en un $25 \%$ de pacientes, especialmente niños. Una tercera parte de pacientes cursan con fiebre algo mayor a 38 ${ }^{\circ} \mathrm{C}$, las elevaciones mayores sugieren complicaciones y su ausencia no excluye el diagnóstico en adolescentes y adultos jóvenes. Un estudio de 1000 pacientes demostró que el 90\% de sujetos que presentaron fiebre tuvieron apendicitis perforada. La fiebre es más común en niños con dolor abdominal de origen apendicular que en pacientes de la misma edad con dolor de una etiología diferente El dolor es el único parámetro constante en la apendicitis aguda, suele aparecer sin pretexto e inicialmente es de tipo visceral y por lo tanto central, referido al espacio comprendido entre los dermatomas T8 y T10, continuo y de baja intensidad. Esta característica, que en ocasiones constituye el motivo de consulta, lleva frecuentemente al diagnóstico erróneo de "gastritis", con las consecuencias predecibles. Cuando aparece la exudación y con ella la afectación del peritoneo parietal, el dolor se localiza en el sitio en que se encuentra el apéndice, convirtiéndose además en tipo continuo con exacerbaciones espontáneas o precipitadas por cualquier movimiento. Por la relación anatómica mencionada, el dolor puede ubicarse hacia el cuadrante superior derecho (apéndice ascendente subhepática), flanco derecho (retrocecal), fosa lumbar derecha (retroperitoneal), mesogastrio (retroileal), área suprapúbica (apéndice pélvico), cuadrante inferior izquierdo (ciego móvil con apéndice largo, situs inversus). 


\section{Escala de Alvarado como método de diagnóstico en apendicitis aguda}

Vol. 2, núm. 2., (2018)

Harry Francisco Álvarez Castro; Franklin Valdez Aguagallo; Lady Diana Ramírez Moran

La taquicardia es un componente asociado con la intensidad del dolor, la gravedad de la enfermedad y la fiebre. Su presencia sugiere complicaciones.

Por lo general no hay cambios en la tensión arterial, pero si aparece hipotensión, suele relacionarse con la deshidratación y la sepsis propia de las peritonitis. El primer paso en la evaluación de una posible apendicitis aguda es el frote delicado del pulpejo del dedo índice para buscar hiperestesia cutánea, maniobra que al ser positiva nos revela la necesidad de buscar rebote peritoneal. La búsqueda de los puntos dolorosos topográficos permiten configurar el diagnóstico y aproximarnos a la posible ubicación del apéndice, por lo que no debe excluirse la valoración de los siguientes sitios clave:

- Punto de McBurney: en la unión del tercio inferior (externo) con el tercio medio de la línea umbílico-espinal derecha. Universalmente presente.

- Punto de Morris: en la unión del tercio medio con el tercio superior (interno) de la línea umbílico-espinal derecha. Se asocia con la ubicación retroileal del órgano.

- Punto de Lanz: en la convergencia de la línea interespinal con el borde externo del músculo recto anterior derecho. El apéndice está dirigido hacia la pelvis.

- Punto de Lecene: a aproximadamente dos centímetros por arriba y por afuera de la espina ilíaca anterosuperior. Positivo en las apendicitis retrocecales.

Existen cinco maniobras complementarias de utilidad en la valoración del paciente:

Maniobra de Rovsing: comprime de manera suave y progresiva el colon izquierdo valiéndose de las eminencias tenar e hipotenar de la mano derecha, lo que provocará molestia en el cuadrante inferior derecho del abdomen por el desplazamiento de las asas de intestino delgado 


\section{Escala de Alvarado como método de diagnóstico en apendicitis aguda}

Vol. 2, núm. 2., (2018)

Harry Francisco Álvarez Castro; Franklin Valdez Aguagallo; Lady Diana Ramírez Moran

contra un foco de inflamación en la fosa ilíaca derecha. Maniobra de Blumberg: se profundiza delicada y progresivamente la palpación en el área apendicular y se retira la mano en un solo movimiento para despertar rebote peritoneal. El signo es exclusivo de la apendicitis aguda y su descripción original indica comprimir y descomprimir en el cuadrante inferior izquierdo (M. Blumberg, cirujano berlinés fallecido en 1955). Maniobra del psoas: flexión de la cadera derecha con la rodilla extendida, en contra de la gravedad. No debe comprimirse simultáneamente la fosa ilíaca y la positividad del signo sugiere una apendicitis retrocecal. Maniobra de Cope o del obturador: con el muslo derecho flexionado se hace una rotación interna de la cadera, lo que despertará dolor en el hipogastrio cuando el apéndice se encuentra dirigido hacia la pelvis, en contacto con el músculo obturador interno. Maniobra de Alders o de la presión cambiante: en mujeres embarazadas permite diferenciar el dolor de origen uterino del de origen apendicular, para lo cual se hace la palpación del sitio de dolor y luego se procede a colocar a la enferma en decúbito lateral izquierdo. Si el dolor es de origen uterino, migrará hacia el lado izquierdo, mientras que si es de origen apendicular se mantendrá en el sitio inicial.

Es posible detectar defensa muscular que llega a la contractura en los casos complicados y ambos datos habitualmente se asocian con la presencia de un plastrón apendicular. Debemos insistir que la existencia de hiperestesia cutánea o rigidez de la pared abdominal convierten en una crueldad la ejecución de la maniobra de Blumberg, porque evidentemente hay severo compromiso peritoneal. Cabe recordar que todos los signos aquí descritos estarán ubicados al lado contrario en los raros casos de situs inversus totalis. La percusión del abdomen pretende cumplir dos objetivos clave: uno, definir con bastante exactitud el sitio de máximo dolor, lo que se logra percutiendo suavemente el hemiabdomen derecho de arriba hacia abajo (la prueba 


\section{Escala de Alvarado como método de diagnóstico en apendicitis aguda}

Vol. 2, núm. 2., (2018)

Harry Francisco Álvarez Castro; Franklin Valdez Aguagallo; Lady Diana Ramírez Moran reemplaza a la del "dedo indicador", de indudable valor diagnóstico). La segunda meta trata de buscar un signo de Jobert positivo, como traducción de neumoperitoneo que puede encontrarse hasta en $2 \%$ de pacientes con apendicitis aguda perforada.

\section{Diagnóstico}

El diagnóstico de la apendicitis aguda se basa estrictamente en la sospecha clínica derivada de una anamnesis bien lograda y de un examen físico intencionado y orientador. Los datos de laboratorio y las ayudas imagenológicas no deben ser realizados de rutina y su papel fundamental debe apuntar a confirmar sospechas antes que a descartar otras posibilidades.

\section{Laboratorio}

\section{Hemograma}

Generalmente existe leucocitosis con un rango entre 12000 y 20000 leucocitos (60\% de pacientes) con desviación a la izquierda. En algunos casos el conteo puede estar en límites normales, pero la fórmula es indicativa de un proceso agudo (94,4\% de casos).

Existe una exagerada dependencia del médico hacia el conteo y la fórmula leucocitaria a la hora de diagnosticar apendicitis. Peor aún, hay una inveterada costumbre a la repetición seriada de este estudio (cada 4 o 6 horas), en los casos de duda. Es muy importante recordar que este proceder carece de valor real, objetivo y práctico y que sólo sirve para desperdiciar recursos y encarecer la valoración del paciente. 


\section{Escala de Alvarado como método de diagnóstico en apendicitis aguda}

Vol. 2, núm. 2., (2018)

Harry Francisco Álvarez Castro; Franklin Valdez Aguagallo; Lady Diana Ramírez Moran

\section{Examen elemental y microscópico de orina}

El estudio elemental y microscópico de la orina y su sedimento no juega papel alguno en el diagnóstico ni en la exclusión de la apendicitis aguda. La justificación para realizarlo debe basarse en la presencia de síntomas urológicos y si bien algunos de estos pueden aparecer en la enfermedad apendicular, la intensidad de los mismos y las características del abdomen son los elementos que hacen el diagnóstico.

Es importante considerar que, por una parte, el dolor abdominal como síntoma aislado no necesariamente justifica el efectuar un análisis de orina y por otra, un estudio anormal no necesariamente debe constituirse en una pauta para modificar el criterio clínico. De hecho, hasta un $20 \%$ de varones con apendicitis presentan albuminuria y leucocituria (con 5 a 20 células por campo, en promedio) y en mujeres es mucho más común la presencia de glóbulos blancos en el sedimento. La hematuria y la bacteriuria también se hacen presentes cuando hay una apendicitis, especialmente complicada, en la vecindad de cualquier segmento del tracto urinario.

\section{Pruebas bioquímicas}

La determinación de la proteína $\mathrm{C}$ reactiva $(\mathrm{PCR})$ parece adquirir un interesante papel en la predicción de la apendicitis aguda. Esta betaglobulina producida en el hígado es un marcador de respuesta aguda que aumenta en cualquier proceso inflamatorio como una respuesta primaria a la destrucción celular. Al parecer la liberación de la PCR es un mecanismo de protección filogenético muy antiguo y poco específico, pero varios autores coinciden en señalar que si bien su elevación resulta inespecífica, los valores normales descartan la posibilidad de apendicitis en pacientes con dolor abdominal de más de 12 horas de evolución.

Revista Científica Mundo de la Investigación y el Conocimiento. 2 (2). pp. 496-524 


\section{Escala de Alvarado como método de diagnóstico en apendicitis aguda}

Vol. 2, núm. 2., (2018)

Harry Francisco Álvarez Castro; Franklin Valdez Aguagallo; Lady Diana Ramírez Moran

Un interesante estudio realizado por Astudillo y colaboradores al determinar PCR en líquido peritoneal mediante punción, concluye que la predicción es muy significativa para apendicitis aguda, especialmente si se convalida con el contaje de neutrófilos.

\section{Imagen}

\section{Radiografía simple de abdomen}

Este estudio es de poca utilidad por cuanto resulta normal en el $50 \%$ de los casos y porque en general sólo ofrece datos indirectos de la enfermedad. El signo más importante es la presencia de un fecalito, observado sólo en $10 \%$ a $15 \%$ de casos pero altamente específico (90\%). Otros signos incluyen la aparición de niveles hidroaéreos en el ciego o el íleon terminal (60\%), íleo local o generalizado (20\% a 40\%), la obstrucción intestinal (10\%), el incremento del espacio parietocólico derecho, la ausencia de la imagen del psoas y de la grasa preperitoneal en el mismo lado, escoliosis antiálgica, neumatización del apéndice (1\% a 2\%), neumoperitoneo (1\% a $2 \%)$ y ausencia de gas intestinal en la fosa ilíaca derecha, que sugiere plastrón. 


\section{Escala de Alvarado como método de diagnóstico en apendicitis aguda}

Vol. 2, núm. 2., (2018)

Harry Francisco Álvarez Castro; Franklin Valdez Aguagallo; Lady Diana Ramírez Moran

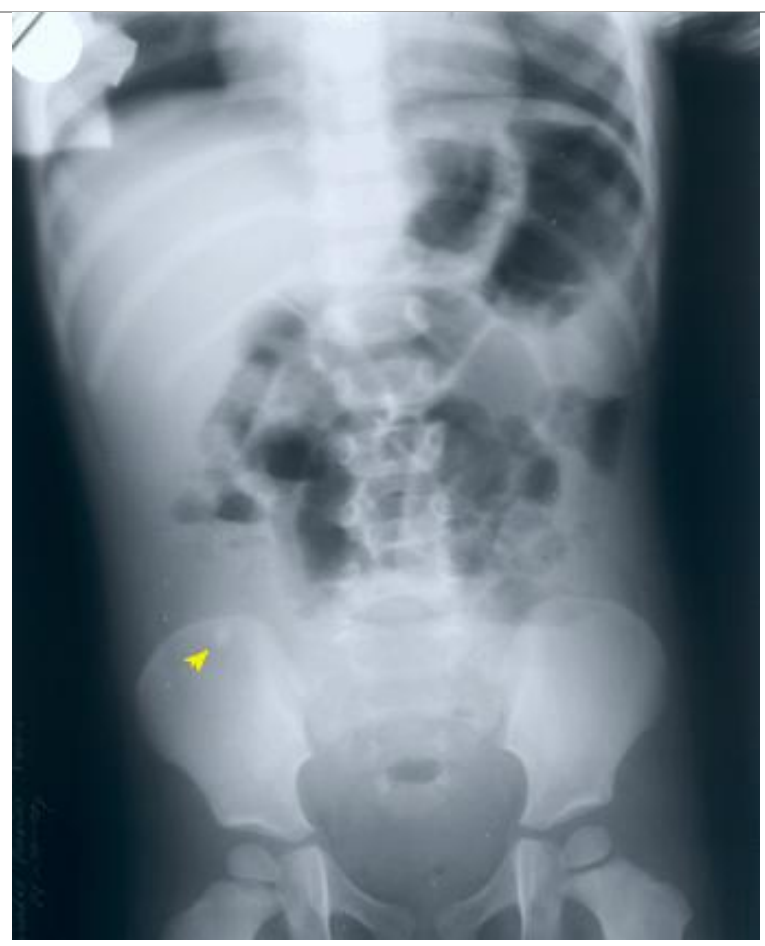

Figura $N^{\circ}$ 1.- APENDICOLITO

\section{Colon por enema}

Es un estudio seguro, simple y confiable cuya mayor aplicación es para enfermos de más de cincuenta años en los que varias patologías pueden semejar una apendicitis. El llenado con bario del lumen apendicular en toda su longitud descarta apendicitis aguda, pero se debe recordar que hasta un $31 \%$ de apéndices normales pueden no presentar opacidad en las imágenes. De ahí que la falta de llenado total o parcial tenga significado diagnóstico sólo cuando se asocia con signos de compresión extrínseca focal sobre el borde anteromedial del ciego o íleon terminal y engrosamiento de la mucosa cecal, signos que ofrecen una exactitud del 91,5\%. 


\section{Escala de Alvarado como método de diagnóstico en apendicitis aguda}

Vol. 2, núm. 2., (2018)

Harry Francisco Álvarez Castro; Franklin Valdez Aguagallo; Lady Diana Ramírez Moran

\section{Ecosonografía}

La detección de una estructura tubular con extremo cerrado en el borde inferior del ciego, que esté llena de líquido, que no sea compresible y que mida más de $6 \mathrm{~mm}$ de diámetro, hace el diagnóstico ecográfico de apendicitis. Es posible detectar también un coprolito, líquido periapendicular y masa inflamatoria, en los casos complicados. Estudios de metanálisis reportan una sensibilidad del $85 \%$ con especificidad del $92 \%$ para el ecosonograma en el diagnóstico de apendicitis y un índice de exactitud global del 93\%.

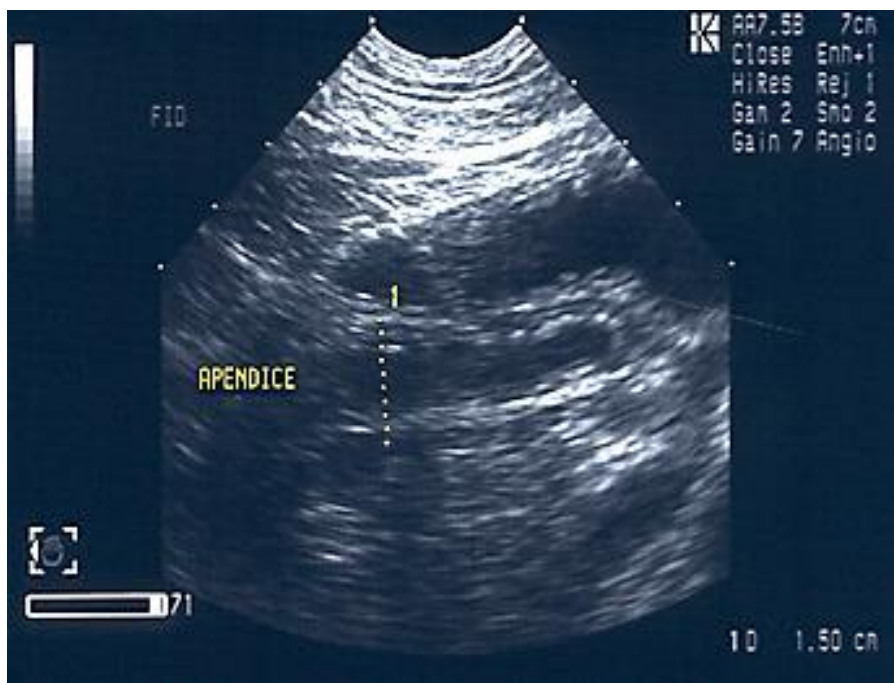

\section{Figura $N^{\circ}$ 2.- APENDICITIS AGUDA EN ECOGRAFÍA}

\section{Tomografía axial computarizada}

La imagen de la apendicitis aguda en la tomografía computarizada implica una estructura tubular mayor a $6 \mathrm{~mm}$ de diámetro que no se llena con el medio de contraste, con pared engrosada en $3 \mathrm{~mm}$ o más, discreto realce con el contraste intravenoso y cambios inflamatorios periapendiculares. Existen algunos signos secundarios que incluyen apendicolito, modificaciones 


\section{Escala de Alvarado como método de diagnóstico en apendicitis aguda}

Vol. 2, núm. 2., (2018)

Harry Francisco Álvarez Castro; Franklin Valdez Aguagallo; Lady Diana Ramírez Moran

en el aspecto del ciego, cambios inflamatorios en el cuadrante inferior derecho (infiltración de la grasa periapendicular, flemón, gas extraluminal, colecciones, adenopatías), engrosamiento focal de la pared del íleon distal y engrosamiento focal de la pared del sigmoides. Los estudios asignan a este método una sensibilidad del $96 \%$ al $98 \%$ y hasta un $89 \%$ de especificidad.

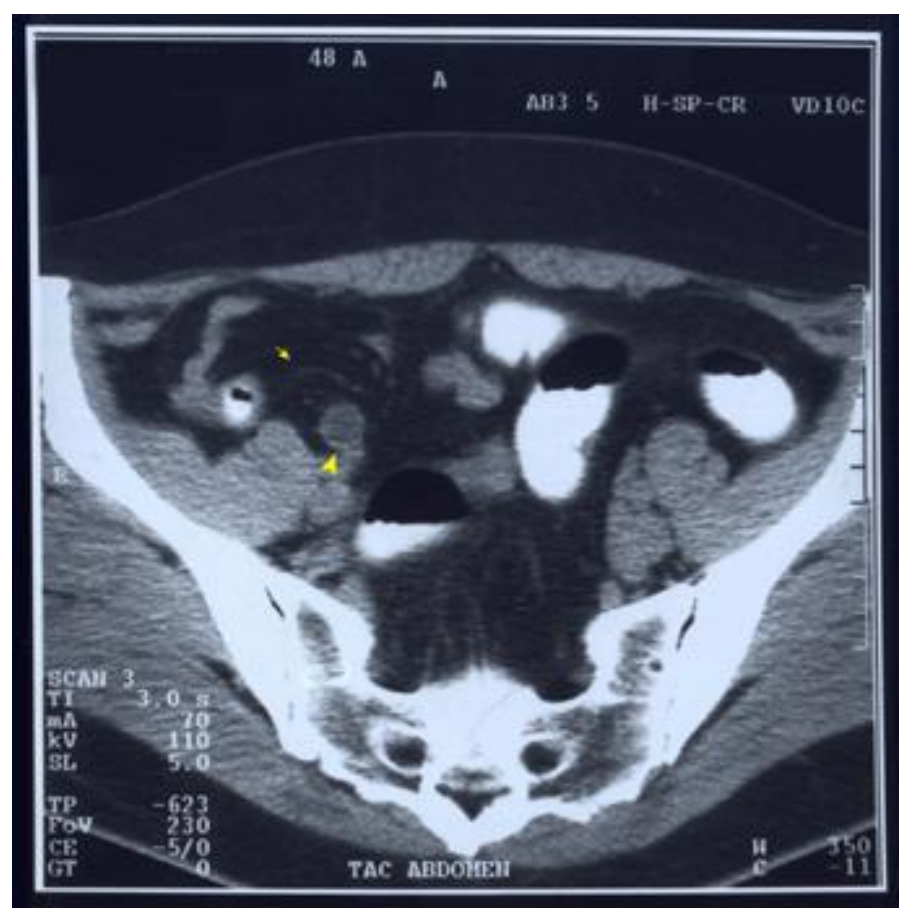

Figura $N^{\circ}$ 3.- APENDICITIS AGUDA POR TOMOGRAFÍA

Manejo inmediato y tratamiento

Los parámetros de manejo ante la sospecha no confirmada de apendicitis aguda incluyen los siguientes pasos: Nada por vía oral. Hidratación basal y de las pérdidas calculadas con solución de lactato de Ringer. Analgesia con un antiinflamatorio no esteroidal. Evaluación repetida del abdomen. 


\section{Escala de Alvarado como método de diagnóstico en apendicitis aguda}

Vol. 2, núm. 2., (2018)

Harry Francisco Álvarez Castro; Franklin Valdez Aguagallo; Lady Diana Ramírez Moran

Si el diagnóstico está confirmado y se trata de una apendicitis no complicada, a lo anterior debe añadirse una antibioticoterapia anticipada con una cefalosporina de segunda generación o con metronidazol por vía rectal. Si se trata de una apendicitis complicada se realizará sistemáticamente un hemograma para definir el estado del proceso y la respuesta inmune. También se efectuarán estudios complementarios para establecer un contexto de todas las complicaciones (por ejemplo hipocalemia, azoemia, etc.). Además se instalará una sonda nasogástrica (por vómito u oclusión asociada), se colocará una sonda vesical (si hay caída del gasto urinario o signos de uremia) y cualquier otro aditamento necesario para monitorizar la fisiología del enfermo. El esquema antibiótico deberá ampliarse para ofrecer cobertura contra Gram-negativos y anaerobios. La analgesia deberá ser suficiente como para mantener totalmente aliviado y cómodo al paciente.

El tratamiento definitivo es la apendicectomía, para lo cual existen dos opciones, la una es a cielo abierto y la otra la constituye la laparoscopia. Cada una de ellas tiene sus ventajas e indicaciones cuya mejor aplicación está en manos del buen juicio del cirujano. La evidencia ha demostrado suficientemente que la cirugía de mínimo acceso es perfectamente aplicable en la gran mayoría de casos. El empleo postoperatorio de antibióticos sigue las pautas universales para el estadio de la enfermedad. En los casos no complicados la antibioticoterapia anticipada se limita sólo a las dosis preoperatorias. En los casos complicados prosigue con una terapia corta (gangrena) o con una estándar (perforada). En todo caso, los criterios para la suspensión de la terapia antiinfecciosa incluyen la ausencia de fiebre por tres días y la evidencia de conteo y fórmula leucocitaria normales. 


\section{Escala de Alvarado como método de diagnóstico en apendicitis aguda}

Vol. 2, núm. 2., (2018)

Harry Francisco Álvarez Castro; Franklin Valdez Aguagallo; Lady Diana Ramírez Moran

\section{Escala de Alvarado}

En 1986 fue propuesta una escala práctica para el diagnóstico temprano de la Dr. Alvarado A. En la que incluyó los síntomas y signos más con sospecha de apendicitis aguda. Consideró ocho características principales extraídas del cuadro clínico de apendicitis agrupadas bajo la nemotecnia MANTRELS por sus siglas en inglés de considerados importantes en la enfermedad, estos son: M - Migración del dolor (a cuadrante inferior derecho)

- A-Anorexia.

- $\quad$ N-Náuseas y/o vómitos.

- $\quad \underline{T}$-Sensibilidad en cuadrante inferior derecho (del inglés Tenderness).

- $\underline{\mathrm{R}-\text { Rebote. }}$

- E-Elevación de la temperatura $>$ de $38^{\circ} \mathrm{C}$.

- $\quad \underline{L}$ - Leucocitosis $>$ de 10500 por mm3.

- $\underline{\mathrm{S}-\text { Desviación a la izquierda }>\text { del } 75 \% \text { (Neutrofilia) }}$

Les asignó un punto a cada característica encontrada, exceptuando sensibilidad en cuadrante inferior derecho y leucocitosis a las que les asignó dos puntos para cada uno totalizando diez puntos y en base al puntaje obtenido determino tres conductas médicas a seguir, estas son: Si la sumatoria es mayor o igual a siete puntos el paciente es candidato a cirugía ya que se considera cursa con apendicitis aguda. Si la sumatoria da entre cuatro y seis puntos se requerirá de valoraciones seriadas tanto clínicas como de laboratorio así como de algunos estudios por imágenes (US, TAC) también a este grupo de pacientes se les puede observar por un tiempo prudente después del cual se les aplicará nuevamente la escala de puntaje para observar si 


\section{Escala de Alvarado como método de diagnóstico en apendicitis aguda}

Vol. 2, núm. 2., (2018)

Harry Francisco Álvarez Castro; Franklin Valdez Aguagallo; Lady Diana Ramírez Moran

ha habido variaciones que permitan confirmar el diagnóstico de apendicitis aguda y operar al paciente o darle tratamiento médico o quirúrgico al tener su diagnóstico y/o egresarlo. Si el puntaje es menor de cuatro existe una muy baja probabilidad de apendicitis ya que muy raros casos se han presentado con menos de cuatro puntos.

La sensibilidad de la escala de A. Alvarado es de $95 \%$ en la población con alta prevalencia de la enfermedad.

\section{Complicaciones de la apendicitis aguda}

\section{Plastrón}

\section{Definición}

Es cuando el epiplón (un tejido laxo que cuelga del intestino grueso) reconoce que existe un proceso inflamatorio e infeccioso que como secuela produce una perforación a nivel del apéndice. Dicho epiplón responde cubriendo la perforación para evitar que se derrame material de la vía digestiva al interior de la cavidad abdominal formando una masa que engloba el proceso.

\section{Diagnóstico}

El signo sobresaliente es la palpación de un tumor de tamaño variable, a veces poco definido y generalmente situado en la FID. Este tumor, de carácter inflamatorio agudo, se puede palpar, en ocasiones, por tacto rectal o vaginal. El plastrón puede estar abscedado. Otra complicación que también obliga a su intervención quirúrgica, es la oclusión intestinal mecánica por acodadura de una de las asas intestinales delgadas que forman parte del proceso. El 


\section{Escala de Alvarado como método de diagnóstico en apendicitis aguda}

Vol. 2, núm. 2., (2018)

Harry Francisco Álvarez Castro; Franklin Valdez Aguagallo; Lady Diana Ramírez Moran

diagnóstico se complementa con el uso de la ultrasonografía y/o la laparoscopía. Se empleará la radiología simple del abdomen, vertical y en decúbito, cuando existan signos de oclusión intestinal mecánica.

Tratamiento

En algunos pacientes, deberán tomarse, al inicio, medidas parecidas a las del período preoperatorio de la apendicitis aguda (ver el presente manual), tales como: Reposo en cama Dieta progresiva, baja en residuos (de acuerdo con el cuadro evolutivo). Antibioticoterapia parenteral. Vigilancia evolutiva, clínica y por exámenes de diagnóstico: pulso, temperatura, palpación del tumor, hemograma y eritrosedimentación.

Si el paciente evoluciona hacia la abscedación, el tratamiento será el drenaje; preferiblemente por punción, guiado por ultrasonografía y de no ser posible éste, entonces se hará quirúrgico. En las formas abscedadas con fístulas espontáneas o fiebre persistente después del drenaje y ante un plastrón de evolución tórpida, se debe sospechar actinomicosis cecoapendicular e instituir tratamiento específico Después de la normalización clínico-humoral se practicará, como parte del seguimiento, colon por enema, para descartar un tumor como responsable del proceso. Tratamiento quirúrgico definitivo: seis meses después de la normalización clínica y humoral, se practicará la apendicectomía. 


\section{Escala de Alvarado como método de diagnóstico en apendicitis aguda}

Vol. 2, núm. 2., (2018)

Harry Francisco Álvarez Castro; Franklin Valdez Aguagallo; Lady Diana Ramírez Moran

\section{Peritonitis difusa}

\section{Definición}

La peritonitis difusa, generalizada o extendida, también denominada sepsis intraabdominal diseminada (SID), se define como el proceso séptico de la cavidad abdominal donde las bacterias, toxinas y esfacelos invaden 2 ó más compartimientos abdominales. Se produce como consecuencia de la contaminación de la cavidad peritoneal por gérmenes procedentes del tracto gastrointestinal, el árbol biliar, el páncreas o el aparato genitourinario, como consecuencia del paso de bacterias a través de los tejidos inflamados o de la perforación espontánea o traumática de estas vísceras, si bien en otras ocasiones se debe a la rotura de abscesos intraabdominales o a la contaminación externa por heridas o traumatismos penetrantes. Entre las principales causas se mencionan: apendicitis aguda, úlcera péptica perforada, obstrucción intestinal con estrangulación, rotura de víscera hueca por perforación tífica o traumática, infecciones pélvicas. (Rodríguez Ramírez, 2010) (Hunt, 1982)

\section{Diagnóstico}

Dolor difuso en el abdomen, con los signos típicos del síndrome peritoneal (contractura, dolor a la percusión y a la descompresión, etc), demás signos de toxinfección (oliguria, polipnea, etc). Tratamiento Laparotomía para eliminar la fuente de contaminación (apendicectomía). Uso adecuado de antibióticos (ver el presente manual). Medidas generales de sostén y contra el shock (ver el presente manual). Lavados peritoneales con soluciones electrolíticas y agentes antimicrobianos; valorando, según el caso, laparotomías programadas o el abdomen abierto. (Quevedo Guanche, 2007) 


\section{Escala de Alvarado como método de diagnóstico en apendicitis aguda}

Vol. 2, núm. 2., (2018)

Harry Francisco Álvarez Castro; Franklin Valdez Aguagallo; Lady Diana Ramírez Moran

\section{Pileflebitis}

Definición Es una tromboflebitis séptica de la vena porta o de algunas de sus ramas tributarias, la cual es una complicación infrecuente de procesos inflamatorios intra-abdominales que además puede acompañarse de abscesos hepáticos. La trombosis de la vena porta puede ocurrir fuera del hígado (extra-hepática) o dentro del hígado (intrahepática). Las causas de la trombosis portal extrahepática incluyen las causas idiomáticas, estados de hipercoagulabilidad, la oclusión por adenomegalias, inflamación de la vena porta debido a pileflebitis ascendente secundario a la infección del apéndice o colon, trombosis de la vena esplénica secundaria a pancreatitis o a procedimientos quirúrgicos abdominales. (ALVAREZ U, GONZÁLEZ L, \& GUTIÉRREZ J, 2002)

Diagnóstico

Al inicio temperatura elevada, escalofríos intensos, leucocitocis; con posterioridad: sangramiento digestivo bajo.

Tratamiento

Antibioticoterapia

Anticoagulantes: del grupo de la heparina hasta obtener el doble o el triple del tiempo normal de coagulación. 


\section{Escala de Alvarado como método de diagnóstico en apendicitis aguda}

Vol. 2, núm. 2., (2018)

Harry Francisco Álvarez Castro; Franklin Valdez Aguagallo; Lady Diana Ramírez Moran

\section{Conclusiones.}

En el presente artículo se logró establecer, que mediante la escala de Alvarado los pacientes presentan un puntaje alto con el que es suficiente para realizar un procedimiento quirúrgico.

La aplicación de la escala de Alvarado debería ser de utilidad en el diagnóstico tentativo de apendicitis en consultorios generales; consultorios rurales; servicios de urgencia que no cuentan con estudios de imagen y tienen una sobrecarga de atención; y en la práctica de médicos y cirujanos con poca experiencia clínica.

La escala de Alvarado constituye una herramienta útil en el diagnóstico clínico de la inflamación del apéndice cecal, fundamentalmente para puntuaciones mayores de 7. La migración del dolor constituyó el elemento específico del puntaje de mejor valor diagnóstico. Esta no permitió discriminar de forma adecuada el posible estado anatomopatológico según el valor de la puntuación obtenida.

\section{Bibliografía.}

ALVAREZ U, R., GONZÁLEZ L, R., \& GUTIÉRREZ J, G. (2002). Tromboflebitis séptica de la vena porta. Revista Chilena de Cirugía, 54(6), 676-680.

BELTRÁN S, M., VILLAR M, R., \& TAPIA, T. (2004). Score diagnóstico de apendicitis: Estudio prospectivo, doble ciego, no aleatorio. Revista Chilena de Cirugía, 56(6), 550557.

Cope, Z. (1947). Diagnóstico precoz del abdomen agudo (12 ed.). Barcelona: Marin editores.

Fallas González, J. (2012). Apendicitis Aguda. Medicina Legal de Costa Rica, 29(1), 83-90.

Hunt, J. (1982). Generalized peritonitis. Arch Surg, 15(2), 117-122. 


\section{Escala de Alvarado como método de diagnóstico en apendicitis aguda}

Vol. 2, núm. 2., (2018)

Harry Francisco Álvarez Castro; Franklin Valdez Aguagallo; Lady Diana Ramírez Moran

López Abreu, Y., Gómez, A., Hernández Paneque, Y., \& Pérez Suárez, M. (2016). Evaluación de la Escala de Alvarado en el diagnóstico clínico de la apendicitis aguda. Revista Habanera de Ciencias Médicas, 15(2), 213-224.

Luz, N. (2017). Factores de Riesgo asociados a apendicitis aguda complicada en pacientes operados en el centro médico naval, en el periodo enero - junio 2016. LIMA: UNIVERSIDAD RICARDO PALMA.

Quevedo Guanche, L. (2007). Complicaciones de la apendicitis aguda. Diagnóstico y tratamiento. Rev Cubana Cir, 46(2), 2-4.

Rengel, C. (2016). Apendicitis Aguda. Su evolución en la Historia. Revista de la Sociedad Venezolana de Historia de la Medicina, 65(2).

Rodríguez Ramírez, R. (2010). Causas, tratamiento y complicaciones de la peritonitis difusa en un hospital de la periferia de Luanda. MEDISAN, 14(8), 1076-1082.

RODRÍGUEZ VEGA, J. (2014). PREVALENCIA DE APENDICITIS AGUDA EN PACIENTES ADULTOS DEL HOSPITAL MARTIN ICAZA Y PROTOCOLO DE MANEJO ACTUALIZADO BABAHOYO 2011. Guayaquil: Universidad de Guaayquil.

Sakellaris, G., Tilemis, S., \& Charissis , G. (2005). Acute appendicitis in preschool-age children. Eur J Pediatr, 163(1), 803-810.

Sanabria, Á., Domínguez, L., Bermúdez, C., \& Serna, A. (2007). Evaluación de escalas diagnósticas en pacientes con dolor abdominal sugestivo de apendicitis. Biomédica, 27(3), 419-428.

Young, P. (2014). La apendicitis y su historia. Revista Médica de Chile, 142(5), 667-672. 